\title{
ПРАВОВОЕ РЕГУЛИРОВАНИЕ БАНКОВСКОЙ ДЕЯТЕЛЬНОСТИ И ЦИФРОВИЗАЦИЯ: ПРОБЛЕМЫ И ПЕРСПЕКТИВЫ РАЗВИТИЯ
}

\section{LEGAL REGULATION OF BANKING \\ AND DIGITALIZATION: PROBLEMS AND PROSPECTS FOR DEVELOPMENT}

\section{Terekhova}

Summary. This article examines the typical problems arising in part of the legal regulation of banking activities in the conditions of digitalization of the economy, as well as the prospects for the main directions of the development of the banking sector under the influence of digital transformation of the entire sphere of government legal relations, which is purposefully implemented in Russia.

The banking sphere today is an integral tool for the development and operation of any economy, actually by the role of its circulatory system, and the spectrum of services rendered by banks is currently very wide and difficult to be a complete comprehensive description.

The Government of the Russian Federation is taken by a course on the widespread digitalization of not only interdepartmental interaction, state and municipal services, but also on the digitalization of the entire sphere of civil legal relations on as much as it is possible to implement technologically. The digitalization of the economic interaction of economic entities and the state allows not only to optimize the available resources, but also increase the efficiency of their use by expanding technological capabilities. Accordingly, the banking sphere does not remain anything, how to follow the established global trend on digitalization, as this allows you to take advantage of a number of new opportunities and advantages.

Keywords: banking, regulation, digitalization, development problems, special legal regimes, development prospects, improving efficiency.
$\mathbf{H}$ а современном этапе развития производственных и социально-экономических отношений банковская система выступает неотъемлемым, если не одним из базовых институтов любой экономической системы. Будучи сложнейшим механизмом любой современной экономики, банковская система направляет свободные финансовые ресурсы, аккумулирующиеся на текущих счетах и вкладах, на кредитное финансирование не только физических лиц, но и хозяйствующих субъектов, нуждающихся в инвестиционном сопровождении своей экономической, в т.ч. инновационной деятельности. При этом именно банки и банковская система берут на себя риски невозврата кредитов и инвестиционных
Терехова Валентина Владимировна

К.ю.н., дочент, Российский государственный гуманитарный университет, г. Москва wsamoilova@mail.ru

Аннотация. В данной статье исследуются типовые проблемы, возникающие в части правового регулирования банковской деятельности в условиях цифровизации экономики, а также перспективы основных направлений развития банковской сферы под воздействием цифровой трансформации всей сферы государственных правоотношений, которая целенаправленно реализуется в России.

Банковская сфера сегодня является неотъемлемым инструментом развития и функционирования любой экономики, фактически исполняя роль ее кровеносной системы, а спектр оказываемых банками услуг в настоящее время весьма широк и с трудом поддаётся полному исчерпывающему описанию.

Правительством Российской Федерации взят курс на повсеместную цифровизацию не только межведомственного взаимодействия, государственных и муниципальных услуг, но и на цифровизацию всей сферы гражданских правоотношений на столько, на сколько это возможно реализовать технологически. Цифровизация экономического взаимодействия хозяйствующих субъектов и государства позволяет не только оптимизировать имеющиеся ресурсы, но и повысить эффективность их использования за счет расширения технологических возможностей. Соответственно, банковской сфере ничего не остаётся, как следовать установившемуся глобальному тренду на цифровизацию, так как это позволяет воспользоваться целым рядом новых возможностей и преимуществ.

Ключевые слова: банковская сфера, регулирование, цифровизация, проблемы развития, специальные правовые режимы, перспективы развития, повышение эффективности.

вложений в результате не оправдавших ожидания, или не окупившихся экономических проектов.

Иными словами, банковская сфера, сама по себя являющаяся мощнейшим регулятором денежного обращения в макроэкономике, самым тесным образом интегрирована с большинством аспектов финансово-кредитной и экономической жизни государства, а банковская кредитная политика непосредственно влияет на состояние всех отраслей экономики.

Появление новой глобальной информационной технологии, которую представляет из себя сеть «Интернет» 
поначалу не оказало сколько-нибудь значимого влияния на процесс взаимодействия между банками и их клиентами, хотя технологии информационных сетей, позволявших быстро и безопасно обмениваться финансовой информацией и осуществлять финансовые транзакции практически сразу была взята на вооружение банковской сферой.

Повышение доступности интернет-технологий спровоцировало формирование множества сервисов, связанных с оказанием услуг и ведением бизнеса, что не могло не затронуть и банковскую сферу, а затем последовал и бурный процесс цифровизации гражданско-правовых отношений, который мы в настоящее время можем наблюдать в частности в России, а также в других развитых странах, который уже начал оказывать колоссальное воздействие практически на все сферы гражданского оборота, традиционно подвергавшиеся правовому регулированию.

Что касается российской банковской системы, то основные направления ее развития определяются целым комплексом регулирующих нормативно-правовых актов, при этом сама теория банковского регулирования в настоящий момент переживает виток активной эволюции, вызванной необходимостью создания качественных инструментов цифровой экономики, в том числе цифровых инноваций в сфере финансовых технологий и сервисов.

Внедрение технологических инноваций в финансовую индустрию является важнейшим глобальным феноменом последних лет, а его темп с каждым годом ускоряется. Применение цифровых технологий для предоставления финансовых услуг стимулирует инновации В финансовой сфере. В целом цифровизация в настоящее время является важным драйвером для развития финансового рынка, появления более удобных и безопасных продуктов и сервисов [1].

В то же время развитие новых финансовых технологий вызывает множество проблем, связанных с правовым регулированием, неспособностью, а в ряде случаев - неготовностью законодательства к кардинальным переменам, и явным отсутствием правового обеспечения новых технологических процессов, в частности в банковской сфере [2].

Вышеописанная ситуация характерна не только для Российской Федерации, но и для абсолютного большинства стран, проводящих целенаправленную политику цифровизации гражданских правоотношений: -практически везде правовое регулирование не только в банковской сфере, но и в других сферах гражданского оборота, далеко не всегда успевает за развитием современных электронных технологий и инноваций.
Более того, в ряде случаев возникают ситуации, когда существующие нормы правового регулирования либо противоречат, либо и вовсе пресекают возможность использования тех иных передовых инновационных технологий и разработок; в частности, такова ситуация с беспилотным транспортом, принцип беспилотности которого до недавнего времени противоречил ряду положений отечественных Правил дорожного движения.

Анализ последних российских законодательных новаций, позволяет прийти к выводу, что проблема «фонового законодательного сдерживания и запрета» на развитие инновационных технологий в современной России на уровне руководства страны явно осознана, и властями уже принимаются меры, направленные на своевременную выработку новых норм правового регулирования, способных обеспечить цифровизацию различных сфер гражданского оборота и экономики, в том числе банковской сферы. При этом российские власти решили выбрать универсальный и весьма эффективный путь, позволяющий находить наиболее адекватные и востребованные решения в части правового регулирования для всех сфер правоотношений, подверженных стремительной цифровизации и внедрению инновационных технологий: с января 2021 года в стране действует Федеральный закон № 258-Ф3 от 31.07.2020 «Об экспериментальных правовых режимах в сфере цифровых инноваций в Российской Федерации» [3], который позволяет по инициативе заинтересованных лиц разрабатывать и устанавливать экспериментальные правовые режимы в сфере, связанной с теми или иными цифровыми инновациями на локальной территории на определенный срок, ограниченный тремя годами, в течение которого экспериментальные правовые нормы могут «оттачиваться» по предложению лиц, их применяющих. По истечении трехлетнего срока нормы экспериментального правового режима подлежат либо отмене, либо интеграции в систему правового регулирования соответствующей сферы правоотношений. К неизбежным минусам данного Закона следует отнести относительную сложность процедуры установления экспериментального правового режима, что не всегда по силу малым инновационным предприятиям, однако для игроков банковской сферы, обладающих существенными финансовыми и иными ресурсами, данное обстоятельство вряд ли будет представлять из себя сколько-нибудь значимое затруднение.

Таким образом, можно достаточно уверенно констатировать, что на законодательном уровне в России сегодня созданы условия, позволяющие обеспечить необходимое правовое сопровождение для внедрения цифровых инноваций в том числе в банковской сфере. Применительно к банковской сфере, использование упомянутого Закона направлено на выработку норм 
правового регулирования, тех сфер и аспектов банковской деятельности, осуществляемой с использованием цифровых технологий, которые не отрегулированы действующим законодательством вовсе, или в случаях, когда действующее законодательство противоречит возможностям технологических разработок. Также необходимо отметить, что в вышеупомянутом Законе прописана невозможность отмены или трансформации конституционных прав граждан и гарантируемых законодательством свобод.

Поскольку цифровизация, банковской сферы с одной стороны повышая доступность, удобство пользования финансовой услугой и снижая ее цену, с другой создает новые, усложняет и обостряет прежние вызовы, основными направлениями развития правового регулирования банковской системы в условиях все более широкого применения технологий электронного взаимодействия, вероятно, следует обозначить следующие:

1. Регулирование правил, порядка и условий эмиссии цифровых валют, а также регулирование рынка цифровых валют, регулирования сферы взаимодействия цифровых и традиционных валют. Вероятно, данное направление в полной мере не может быть отрегулировано лишь национальным законодательством, и здесь необходимы определенные международные договоренности.

2. Обеспечение безопасности транзакций и платежей, безопасности и независимости передачи межбанковских сообщений. В частности в середине второго десятилетия XXI века глобальная экономика могла похвастаться единой и единственной системой международной межбанковской системы передачи информации и совершения платежей Общества всемирных межбанковских финансовых каналов связи (Society for Worldwide Interbank Financial Telecommunications (SWIFT), позволяющей финансовым учреждениям во всем мире отправлять и получать информацию о финансовых операциях в безопасной, стандартизированной и надежной форме. Данная система была вполне достаточна и универсальна для мировой экономики, пока не выяснилось, что она весьма зависима от отдельных глобальных игроков, отключение по воле которых других участников международной торговли может стать эффективным инструментом недобросовестной конкуренции и политического давления. Соответственно представляется целесообразным разработка не только норм правового регулирования, но и технологических решений, способных обеспечить безопасность и цифровой суверенитет участников межбанковского обмена информацией. Данная задача, очевидно, не может быть решена в полной мере исключительно в границах одного государства и здесь необходимо международное взаимодействие всех заинтересованных субъектов мировой экономики, включая не только государственные образования, но и транснациональные корпорации. С большой долей вероятности можно прогнозировать развитие в обозримом будущем нескольких международных систем, альтернативных SWIFT, полностью позволяющих дублировать ее функции и доступных для всех субъектов глобальной экономики.

3. Обеспечение безопасной идентификации клиентов и пользователей цифровых банковских систем. Сохранение персональных данных и личной информации пользователей при одновременном обеспечении оперативной доступности всех необходимых сведений службам, занятым противодействием терроризму, экстремизму и экономическим преступлениям.

4. Правовое регулирование, направленное на обеспечение унификации, стандартизации и повышения доступности и оперативности типовых банковских услуг посредством личного кабинета пользователя. Здесь можно ожидать развития правой регламентации уровня и объема банковских услуг, предоставляемых в зависимости от устройства доступа и уровня идентификации пользователя. В настоящее время, по крайней мере в России, банки достаточно вольно устанавливают подобные критерии самостоятельно.

5. Правовое регулирование использования биометрии при оказании банковских услуг. В частности, уже сейчас в России доступны сервисы, биометрической идентификации граждан, в том числе детского возраста. Соответственно данные о совершаемых транзакциях и связанная с ними аналитика может накапливаться и использоваться финансовыми учреждениями в том числе в целях обмена и продажи обезличенной информации, тем не менее позволяющей оперировать цифровым слепком личности (цифровым следом) пользователя. Цели сбора и анализа такой информации, порядок ее использования и ликвидации в нашей стране, как и в большинстве других стран до конца не отрегулирован на правовом уровне. Единственным ограничителем здесь пока является лишь законодательство об охране персональных данных.

Соответственно, главным правовым аспектом, остро нуждающимся в регулировке в связи с развитием упомянутых сервисов, является порядок и технология блокирования или изъятия такой накопленной информации, в т.ч. накопленной в несовершеннолетнем возрасте, по граж- 
данам, поступившим на службу связанную с внешней и внутренней разведкой, либо граждан, подпадающих под программы защиты судей, свидетелей и т.п. Здесь необходима, либо проработка правовых норм и технологий по ограничению доступа к такой информации, либо разработка правового порядка возложения ответственности на банковские учреждения в части сохранения информации, относимой законодательством Российской Федерации к сведениям, составляющим государственную тайну, или доступ к которым ограничен.

Таким образом, на сегодняшний день в ряде секторов экономики, в т.ч. в банковском секторе сложилась ситу- ация, когда существующие нормы правового регулирования существенно отстают от технологического развития и возможностей, предоставляемых цифролизацией, и в настоящее время, в частности в Российской Федерации, предпринимаются попытки выработки адекватных, жизнеспособных правовых норм для нового типа цифровизованных форм гражданского оборота. Также представляется очевидным, что в ближайшей перспективе цифровизация банковской сферы позволит не только расширить спектр предоставляемых финансовых услуг и повысит их качество, безопасность и эффективность, но и может сложиться исключительно в электронном виде.

\section{ЛИТЕРАТУРА}

1. «0сновные направления развития финансового рынка Российской Федерации на период 2019-2021 годов» [Электронный ресурс] // Центральный банк Российской Федерации. URL: http://old.cbr.ru/Content/Document/File/71220/main_directions.pdf (дата обращения: 04.04.2021).

2. Боташева Л.Э., Первышев Е.А. Финансово-правовое регулирование банковской деятельности: актуальные направления в условиях цифровизации. // Проблемы экономики и юридической практики. 2018. № 4. С 130-131.

3. Федеральный закон от 31.07.2020 № 258-Ф3 «06 экспериментальных правовых режимах в сфере цифровых инноваций в Российской Федерации» [Электронный ресурс] // Справочная правовая система «Консультант Плюс». URL: http://www.consultant.ru/document/cons_doc_LAW_358738/ (дата 06ращения: 04.04.2021).

(c) Терехова Валентина Владимировна (wsamoilova@mail.ru ).

Журнал «Современная наука: актуальные проблемы теории и практики»

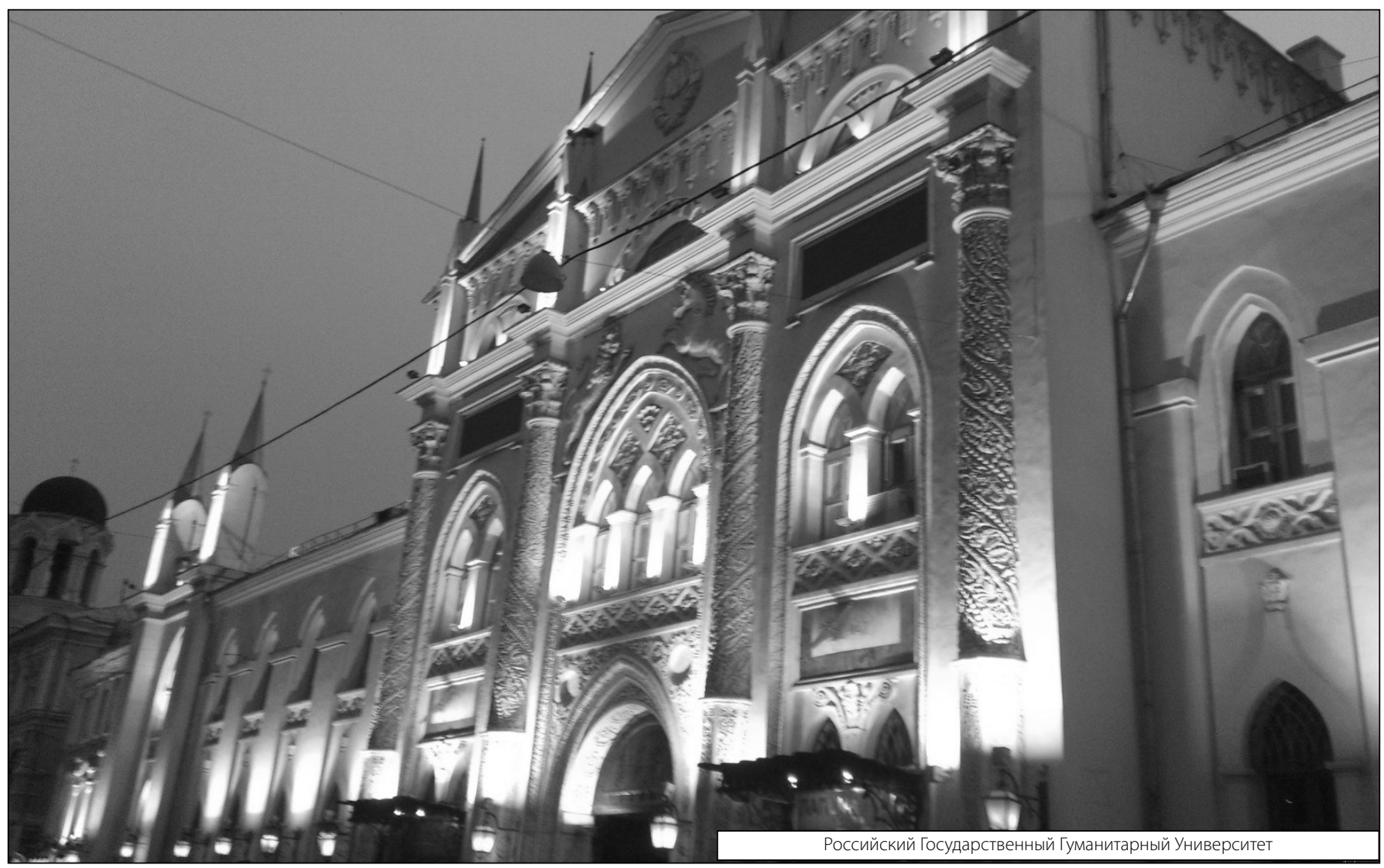

